\title{
BONPLANDIA
}

\section{Una nueva especie de Nicotiana de la flora argentina}

\author{
por RAUL MARTINEZ-CROVETTO
}

\section{Nicotiana paa, nov sp.}

Herba perennis. Rhizoma crasso, horizontalis. Caulis pauci ramosis, $60-80 \mathrm{~cm}$ alt., ad basim $6-8 \mathrm{~mm}$ crassis, glabratis, foliosis, leniter striatis. Foliis $12-15 \mathrm{~cm}$ long. (petiolus inlusus), $25-30 \mathrm{~mm}$ lat. Lamina vix crassa, oblongo lanceolata, margine integerrima vel leviter sparseque denticulata haud undulata, apice leviter rotundata, ad basim longissime attenuata, supra glabra, infra breviter sparseque pilosa. Petıolo quam limbus brevior, leniter bialatus. Foliis supremis linearis, sessiles vel breviter petiolatis. Flores pseudo racenosis, pedicellı bracteolatis $4-7 \mathrm{~mm}$ long; Calyx anguste campanulatus, glabrescens vel ad basim pilis sparsis vestitus, $9-10 \mathrm{~mm}$ long., $1,8-3 \mathrm{~mm}$ crassus, basi rotundata. Corolla alba, infundibuliforme, extus leniter puberula; tubus rectus, sub-cylindricus, ad basim $1,5 \mathrm{~mm}$ crassus, subtus faucem 3-3,5 mm crassus, 35-40 $\mathrm{mm}$ long. (limbus exclusus); limbus 20-25 mm lat., segmentis leviter emarginatis. Stamina 5, inclusa, inaequalia; filamentis glabris, ad basim geniculatis, longiores $26 \mathrm{~mm}$ long., interjacentes $20 \mathrm{~mm}$ long., brevior $12 \mathrm{~mm}$ long.; antherae circulare, 2,2 $\mathrm{mm}$ long. Ovarium ovoideum, glabrum; stylus gracilis, c. $35 \mathrm{~mm}$ long; stigmata asymmetrica, 1,6 $\mathrm{mm}$ long. Capsula ovato acuminata, 11-12 mm long., $5 \mathrm{~mm}$ crassa. Semina compressa, 0,5-0,6 mm long.

Specim. exam.- Argentina: Chaco, depto. Campo del Cielo, Colonia General Belgrano, leg. R. Martínez Crovetto n ${ }^{\circ} 11.305$, XII-1969 (CTES, holotypus).

Hierba perenne. Rizoma horizontal entre 0,10 y $0,20 \mathrm{~m}$ de 
profundidad, algo carnoso cuando fresco, con corteza de color pardo chocolate, fuerte e irregularmente estriado cuando seco. Tallos erectos, poco ramosos, de 0,60 a $0,80 \mathrm{~m}$ de altura por 6 a $8 \mathrm{~mm}$ de diámetro en la base, suavemente estriados, glabrescentes, regularmente foliados. Hojas oblongo lanceoladas, de 12 a $15 \mathrm{~cm}$ de largo (incluyendo el pecíolo) por 2,5 a $3 \mathrm{~cm}$ de ancho en la parte media. Lámina apenas crasa, margen integérrimo o esparcida y remotamente denticulado, no ondulado, ápice brevemente redondeado, largamente atenuado hacia la base, prolongándose en el pecíolo en forma de dos alas muy estrechas, glabras arriba, esparcidamente pilósulas debajo. Flores terminales, en seudo-racimos plurifloros con algunas hojuelas lineares a linearlanceolada, de 3 a $4 \mathrm{~cm}$ de largo, sésiles o cortamente pecioladas. Pedicelos bracteolados, de 4 a $7 \mathrm{~mm}$ de largo (10 a $12 \mathrm{~mm}$ en la fructificación). Cáliz angostamente acampanado, glabrescente o con algunos pelos esparcidos en la base, 9 a $10 \mathrm{~mm}$ de largo por $2,8 \mathrm{~mm}$ de diámetro, base redondeada, dientes algo desiguales. Corola blanca, infudibuliforme, pubérula exteriormente; tubo (o parte tubular) estrecho, alargado, recto, con leve ensanchamiento en la garganta, de 35 a $40 \mathrm{~mm}$ de largo (excluído el limbo) por 1,5 $\mathrm{mm}$ de diámetro, con segmentos ligeramente emarginados. Estambres inclusos, dos de ellos más largos que los restantes con filamentos de unos $26 \mathrm{~mm}$ de largo, dos intermedios con filamentos de unos $20 \mathrm{~mm}$ de largo y uno más corto de unos $12 \mathrm{~mm}$ de largo; éstos insertos en el tercio inferior del tubo, glabros, fuertemente acodados y con pelos en el punto de inserción; anteras casi circulares, glabras, de $2,2 \mathrm{~mm}$ de largo. Ovario ovoide alargado, atenuado hacia el ápice, glabro; estilo verdoso, de unos $35 \mathrm{~mm}$ de largo, grácil; estigma asimétrico, de 1,6 $\mathrm{mm}$ de largo. Cápsula ovada, atenuada en el ápice, de 11 a $12 \mathrm{~mm}$ de largo por $5 \mathrm{~mm}$ de diámetro. Semillas numerosas, comprimidas, subreniformes, pardo grisáceas, reticuladas, de 0,5-0,6 $\mathrm{mm}$ de largo.

Material estudiado.- Además del holótipo y con la misma procedencia, Martínez Crovetto $\mathrm{n}^{\circ}$ M-320, XII-1966, cultivado por indios mocovies a partir de semillas procedentes del norte de Santiago del Estero (CTES).

Observaciones.-- La nueva especie pertenece al subgénero Petunioides (Don) Goodspeed, sect. Noctiflorae Goodspeed',

1 En Univ. Calif. Publ. Bot. 18: 340, 1945 y en The genus Nicotiana p. 411, 1954, Waltham. 
aunque las diferencias establecidas por su autor con relación a la sect. Acuminatae Goodsp. no parecen ser muy claras. De cualquier manera, difiere de todas ellas porque consta de un rizoma (o raíz gemífera?) horizontal que, bajo tierra, emite brotes verticales. De acuerdo con la descripción e ilustraciones que suministra dicho autor ${ }^{2}$, la especie que más se parece es Nicotiana noctiflora, por el tamaño de las flores, pero existen grandes diferencias por cuanto esta última es anual o limitadamente perenne y por la forma de las hojas. La sect. Acuminatae sólo incluye especies anuales.

El epíteto específico propuesto deriva del vocablo paá', que es el nombre vulgar aplicado por los indios mocovíes, quienes suelen usar sus raíces secas y picadas para fumarlas en pipa. Esto, que antiguamente era muy común, ha venido cayendo en desuso al ser reemplazadas por el tabaco comercial. Las primeras plantas que tuve ocasión de ver en 1964, habían sido obtenidas de semillas traídas, según el aborigen mocoví que las tenía en cultivo, del norte de Santiago ciel Estero, donde crecía silvestre. En años posteriores fueron apareciendo nuevas plantas en los alrededores, en parte por rebrotación radicular y en parte por semillas. En macetas, en el jardín botánico ae la Facultad de Ciencias Agrarias, planté algunos trozos de rizomas, los cuales brotaron, pero luego, por causas climáticas adversas e insuficiencia de riego, las plantas murieron.

De las semillas que traje en varias oportunidades no obtuve éxito, pues, aparentemente, pierden el poder germinativo rápidamente. Ello explicaría la escasa difusión de Nicotiana paa en el ámbito chaqueño.

Las medidas indicadas en la descripción corresponden a material seco y, en el caso de órganos florales, a material hervido.

\section{Summary}

The author gives the description of the new species Nicotiana paa, coming from the Austro Chaco region, wich roots are used as tobacco by Mocovi Indians. 